\title{
Retraction Note to: Wu, P., Shi, J., Zhang, Y. et al. The bioremediation of metolachlor in soil using Rhodospirillum rubrum after wastewater treatment
}

\author{
Philip N. Owens ${ }^{1} \cdot$ Zhihong $\mathrm{Xu}^{2}$ \\ Published online: 13 December 2020 \\ (C) Springer-Verlag GmbH Germany, part of Springer Nature 2020
}

Retraction Note to: J Soils Sediments 19, 3534-3544 (2019)

https://doi.org/10.1007/s11368-019-02279-6

The Editors-in-Chief have retracted this article [1] because it contains material that substantially overlaps with another article [2]. Co-author Pan $\mathrm{Wu}$ has informed us that he is the sole author responsible for this submission and included the other listed co-authors without their knowledge or consent. Pan $\mathrm{Wu}$ and Ying Zhang have agreed to the retraction note. Jiarong Shi, Yanling Wang, Xiaoxia Ou, Ziqiao Han, Xiaozhen Wu, Rou Zhao and Weiguang Yang have not responded to any correspondence from the editor/ publisher about this retraction.

The online version of the original article can be found at https://doi.org/ 10.1007/s11368-019-02279-6

Philip N. Owens

Philip.Owens@unbc.ca

Zhihong Xu

zhihong.xu@griffith.edu.au

1 Environmental Science Program and Quesnel River Research Centres, University of Northern British Columbia, Prince George, British Columbia V2N 4Z9, Canada

2 Environmental Future Research institute, School Environment and Science, Griffith University, Nathan, Queensland 4111, Australia
[1] Wu, P., Shi, J., Zhang, Y. et al. The bioremediation of metolachlor in soil using Rhodospirillum rubrum after wastewater treatment. J Soils Sediments 19, 3534-3544 (2019). https://doi.org/10.1007/s11368-019-02279-6

[2] Wu, P., Cao, B., Zhang, Y. et al. The bio-mitigation of acetochlor in soil using Rhodopseudomonas capsulata in effluent after wastewater treatment. J Soils Sediments 19, 2927 2933 (2019). https://doi.org/10.1007/s11368-018-2201-2

Publisher's note Springer Nature remains neutral with regard to jurisdictional claims in published maps and institutional affiliations. 